\title{
VERTICAL MARGINAL GAP DISTANCE AND RETENTION OF DIFFERENT CAD/CAM CERAMIC ENDOCROWNS WITH TWO PREPARATION DESIGNS
}

\author{
Reham Elbasty*; Adel Eltannir** and Atef Shaker**
}

\begin{abstract}
Statement of the problem: The rehabilitation of severely damaged coronal hard tissue and endodontically treated teeth has always been a challenge in reconstructive dentistry. These teeth have been shown to exhibit a significantly shorter service life and an increased failure rate when compared with vital teeth.
\end{abstract}

Objective: This study evaluated the vertical marginal gap distance and retention of bonded CAD/CAM Ceramic Endocrowns as a conservative alternative in endodontically treated molar teeth following thermal cycling and fatigue loading compared to post and core supported Ceramic crowns.

Methods: Ninty caries free human molar teeth were selected and mounted in epoxy resin blocks. For vertical marginal gap distance test, sixty teeth were assigned into six groups $(n=10)$ according to type of restoration as follows; GroupI: Endodontically treated teeth incorporating $1 \mathrm{~mm}$ ferrule restored with IPS Empress CAD endocrowns. Group II: Endodontically treated teeth incorporating $1 \mathrm{~mm}$ ferrule restored with IPS e.max CAD endocrowns. Group III: Endodontically treated teeth without incorporating ferrule restored with IPS Empress CAD endocrowns. Group IV: Endodontically treated teeth without incorporating ferrule restored with IPS e.max CAD endocrowns. Group V: Endodontically treated teeth incorporating $1 \mathrm{~mm}$ ferrule restored with glassfiber posts, composite cores and IPS Empress CAD crowns serving as a control group. Group IV:Endodontically treated teeth incorporating $1 \mathrm{~mm}$ ferrule restored with glass-fiber posts, composite cores and IPS e.max crowns serving as another control group. For retention test, thirty teeth were divided into six groups $(n=5)$. Same designs and types of restorations for the previous test were used for the retention test. All teeth were sectioned perpendicular to the long axis $2 \mathrm{~mm}$ coronal to the proximal CEJ and then subjected to a standard endodontic treatment. A special milling machine was used for teeth preparation. All-Ceramic endocrowns and crowns were constructed using the Cerec InLab system and cemented with Rely x ARC dual cure adhesive resin cement. The vertical marginal gap distance was measured after cementation using a stereomicroscope. Measurements

*Lecturer of Fixed Prostodontics, Faculty of Oral and Dental Medicine, Cairo University.

***Professor of Fixed Prostodontics, Faculty of Oral and Dental Medicine, Cairo University. 
were made at twenty points for each specimen. In order to mimic the intraoral conditions, all the specimens were subjected to thermal cycling and fatigue loading in a pneumatic fatigue device. Mechanical fatigue was performed for 1,200,000 cycles in a water bath subjected to temperature changes between $5^{\circ} \mathrm{C}$ and $60^{\circ} \mathrm{C}$. The vertical marginal gap distance was re measured at the same points to determine the effect of thermal cycling and fatigue loading. Retention was measured by dislodging the crowns along the long axis of the tooth using a computer controlled universal testing machine. The recorded data were tabulated and statistically analyzed.

Results: Regarding the vertical marginal gap distance; endocrowns with $1 \mathrm{~mm}$ ferrule showed the statistically significant highest mean gap distance. There was no statistically significant difference between endocrowns without ferrule and post \& core supported crowns. For endocrowns with $1 \mathrm{~mm}$ ferrule; Empress CAD scored statistically significant higher mean marginal gap values than e.max CAD. There was a statistically significant increase in mean gap distance after thermal cycling and fatigue loading for all test groups. Regarding the retention; endocrowns with $1 \mathrm{~mm}$ ferrule showed the statistically significant highest mean retention value. Post \& core supported crowns showed statistically significant lower mean value. While, endocrowns without ferrule recorded the lowest mean retention value. In both endocrowns with $1 \mathrm{~mm}$ ferrule and post and core supported crowns e.max CAD scored statistically significantly higher mean retention values than Empress CAD, while for the endocrowns without ferrule there was no statistically significant difference between e.max CAD and Empress CAD.

Conclusions: Endocrowns represent a successful conservative alternative to post and core supported crowns for restoring mutilated endodontically treated posterior teeth. All tested endocrown designs with both materials proved to have a clinically acceptable marginal gap distances. Preparation geometry for endocrown designs is a crucial factor for the retention of this kind of restorations.

\section{INTRODUCTION}

The restoration of endodontically treated teeth with extensive tooth loss and minimal macroretentive features is of particular clinical interest.

Endodontically treated teeth are known to present a higher risk of biomechanical failure than vital teeth..$^{(1,2,3)}$ The primary reason for the increased failure rate of endodontically treated teeth is the loss of structural integrity associated with caries, trauma, extensive cavity preparation and endodontic procedures (endodontic access and root canal preparation) rather than dehydration or physical changes in the dentin which proved to have a negligible influence on tooth biomechanical behavior. ${ }^{(4,5,6,7)}$

The classical approach for restoring endodontically treated teeth is to build up the tooth with a post and core then construct a full coverage crown. Although this treatment option proved a clinical success, however the true breakthrough in the restoration of endodontically treated teeth was the introduction of adhesion, propelled by the development of effective dentin adhesives. ${ }^{(8,9)}$

The chief advantage of adhesive restorations is that macro-mechanically destructive preparations are no longer mandatory as long as enough surfaces are available for bonding. In addition, adhesive restorations offer the ability to stabilize hard tissues, making preservation of the residual hard tooth structure of severely destroyed teeth possible. ${ }^{(8,10,11,12)}$ With this approach, the insertion of radicular posts has become the exception rather than the rule. In fact, minimally invasive preparations, with maximal tissue conservation, are now considered the gold standard for restoring endodontically treated teeth. ${ }^{(13)}$

The Endocrowns strictly follows this rationale. They are economical in terms of time and money, 
for there is no need for buildups and posts. The endocrowns also present the advantage of reducing the effect of multiple interfaces in the restorative system and offering greater thickness of the ceramic occlusal portion when compared with a classical crown. In addition, they prevent interferences with periodontal tissues, thanks to a supragingival margin position of the restoration margins. ${ }^{(14)}$

Several studies showed the potential of this restorative approach to provide adequate function and esthetics, even with compromised tooth integrity of non-vital teeth.

Continuous development of both ceramic materials and fabrication techniques in addition to recent advances in bonding materials allowed for the production of restorations with improved retention and marginal adaptation. ${ }^{(15)}$ Achievement of a close marginal adaptation together with good retention are crucial for the long term prognosis of the restoration and its longevity. ${ }^{(16,17)}$

The presence of marginal discrepancies in the restoration exposes the luting agent to the oral environment. In addition, marginal discrepancies have been proven to be responsible for plaque accumulation, periodontal diseases and esthetic problems such as staining or marginal discoloration that might ultimately result in failure of the restoration. ${ }^{(18)}$

The retentive strength of the crowns depends on many factors such as, the preparation height and convergence angle, type of cement used and its adhesive capacity, cement film thickness and its solubility. ${ }^{(19)}$ There is also a direct relationship between retention and the surface area of cement coverage. ${ }^{(20)}$

Thermal cycling and fatigue loading are important factors in regard to the clinical performance of restorations. Clinically, all-ceramic restorations are subjected to masticatory forces in aqueous environment. Since the forces applied are more likely to be of cyclic nature and well below the ultimate strength of the restoration, therefore thermal cycling and fatigue loading mimics more accurately the intraoral conditions..$^{(21)}$

According to the hypothesis that endocrowns achieve survival rates similar to post and core supported crowns, this study was conducted to evaluate the vertical marginal gap distance and retention of CAD/CAM ceramic Endocrowns with two preparation designs following thermal cycling and fatigue loading compared to post and core supported ceramic crowns.

\section{MATERIALS AND METHODS}

\section{Materials used in the study were:}

1- IPS Empress CAD (Leucite-reinforced glass ceramic) blocks. (Ivoclar Vivadent, Schaan, Liechtenstein)

2- IPS e.max CAD (Lithium disilicate glass ceramic) blocks. (Ivoclar Vivadent, Schaan, Liechtenstein)

3- RelyX ARC dual-cure adhesive resin cement. (3M ESPE, Seefeld, Germany)

4- FibreKleer tapered glass fiber posts. (Pentron Clinical, CA, USA)

5- Build-It Fiber reinforced dual-cure core buildup material supplied in auto-mix syringes. (Pentron Clinical, CA, USA)

\section{Teeth selection and grouping}

Ninty extracted human molar teeth, free of cracks, fractures or cervical wear were used in this study. The anatomic crowns were selected to be with average dimensions after measuring the buccolingual and mesio-distal widths at the level of the cementoenamel junction using a digital caliper. The selected teeth were cleaned with an ultrasonic scaler and then kept hydrated at room temperature in distilled water prior to the study. 
All teeth were mounted in epoxy resin blocks. A special device (parallelometer) was fabricated to allow an accurate vertical centralization of the teeth in the blocks with the mid-facial extent of the cementoenamel junction located $2 \mathrm{~mm}$ coronal to the resin top surface.

Before any intervention, all teeth were scanned, as the "crown/biogeneric copy" mode was used for the construction of the Cerec crowns and endocrowns. Teeth were sprayed with an optical reflection medium and scanning was done using inEos Blue scanner (Sirona Dental System, Bensheim, Germany) then obtained virtual image was archived in the Biogeneric copy catalogue of the software.

For vertical marginal gap distance test, 60 teeth were randomly divided into six groups of ten samples each, according to the type of restoration as follows; Group I: Endodontically treated teeth incorporating $1 \mathrm{~mm}$ ferrule restored with IPS Empress CAD endocrowns. Group II: Endodontically treated teeth incorporating $1 \mathrm{~mm}$ ferrule restored with IPS e.max CAD endocrowns. Group III: Endodontically treated teeth without incorporating ferrule restored with IPS Empress CAD endocrowns. Group IV: Endodontically treated teeth without incorporating ferrule restored with IPS e.max CAD endocrowns. Group V: Endodontically treated teeth incorporating $1 \mathrm{~mm}$ ferrule restored with glass-fiber posts, composite cores and IPS Empress CAD crowns serving as control group. Group VI: Endodontically treated teeth incorporating $1 \mathrm{~mm}$ ferrule restored with glass-fiber posts, composite cores and IPS e.max crowns serving as another control group. For retention test, 30 teeth were randomly divided into six groups of five samples each. Same designs and types of restorations for the previous test were used for the retention test.

\section{Teeth preparation}

All teeth were sectioned perpendicular to the long axis $2 \mathrm{~mm}$ coronal to the proximal CEJ, using a super coarse diamond disc and copious irrigation. For the post and core supported group, a rubber index was made for the clinical crown of each tooth prior to decapitation using addition silicone impression material then all teeth were subjected to a standard endodontic treatment.

\section{For groups I and II: (Endocrowns with 1mm fer-}

rule) Gutta percha was removed till the canals entrance with no more drilling inside the canals. A thin layer of flowable composite material (Filtek Z350, 3M ESPE Dental products, St. Paul, USA) was bonded to seal the canals entrance. A special milling machine* was used for teeth preparation. The assembly incorporates a conventional-speed straight hand-piece perpendicular to the surveyor platform.

The endodontic access cavity was prepared with a $10^{\circ}$ coronal divergence. Extracoronally, the remaining vertical portion of the crown was prepared with a circumferential $90^{\circ}$ shoulder margin $1 \mathrm{~mm}$ wide with rounded internal line angles, located on sound tooth structure $1 \mathrm{~mm}$ from the cementoenamel junction leaving a $1 \mathrm{~mm}$ ferrule, and with a $10^{\circ}$ convergence angle. (Fig.1A)

\section{For groups III and IV: (Endocrowns without} ferrule) The endodontic access cavity was prepared with a $10^{\circ}$ coronal divergence as in groups I and II but with neither extra coronal preparation nor ferrule incorporation. (Fig.1B)

\section{For groups V and VI: (Post and core supported} crowns) For each tooth, post space preparation began with the removal of gutta percha to a depth of $10 \mathrm{~mm}$ from the coronal tooth structure using gates glidden drills, then FibreKleer post tapered drill was used to remove any residual root filling and complete canal preparation. Each glass fiber post was reduced to a length of $12 \mathrm{~mm}$ resulting in a dowel extending $2 \mathrm{~mm}$ above the coronal surface of the trimmed crown.The root canal was etched with $35 \%$ phosphoric acid (Scotchbond etchant, 3M ESPE Dental products, St. Paul, USA) for $15 \mathrm{sec}-$ 
onds, washed with water spray, and then the excess water was removed from the post space using paper points.Subsequently, adhesive bonding agent (Adper Single bond 2 adhesive, 3M ESPE Dental products, St. Paul, USA) was applied with a microbrush in two consecutive coats and gently air-dried.

RelyX ARC dual-cure resin cement was used for luting of glass-fiber posts. The cement was hand mixed for 10 seconds and applied into the canal with the use of a periodontal probe. A thin layer of cement was also placed on the post surface after being silanized with ceramic primer (RelyX Ceramic Primer, 3M ESPE Dental products, St. Paul,USA) for 60 seconds. Then the post was inserted into the canal. Excess resin cement was removed with a clean microbrush and then light polymerized for 40 seconds.

For crown reconstruction, the remaining tooth structure was etched followed by the application of adhesive bonding agent as described before. BuildIt Fiber reinforced dual-cure core material was injected in the previously constructed rubber index which was then positioned on the corresponding tooth and left for 5 minutes for primary setting. Then the index was removed and complete polymerization was achieved by light curing for 40 seconds for each surface. Axial walls were then prepared with a circumferential $90^{\circ}$ shoulder margin $1 \mathrm{~mm}$ wide with rounded internal line angles, located on sound tooth structure $1 \mathrm{~mm}$ from the cementoenamel junction leaving a $1 \mathrm{~mm}$ ferrule, and with a $10^{\circ}$ convergence angle. Occlusal reduction of $2 \mathrm{~mm}$ was performed. The constructed rubber index was sectioned vertically into 2 halves to help in verifying the amount of occlusal reduction. (Fig.1C)

\section{Construction of Cerec CAD/CAM endocrowns and crowns}

A CAD/CAM system (Cerec InLab SW 4.0) was used for the fabrication of all samples in this study. To obtain a three dimensional image for each prepared tooth, the prepared tooth was sprayed using an optical reflection medium, scanned using the In-Eos blue scanner, then the captured picture was saved in the preparation catalogue of the software. The software calculated a virtual model from the scanned pictures and an automatic margin finder was used for preparation margin detection. With the aid of both Cerec InLab software and the biogeneric copy option, the scanned unprepared tooth was correlated to the preparation in order to construct a virtual endocrown and crown identical to the tooth form before preparation. For the retention test specimens, the endocrowns and crowns were designed with exaggerated proximal contours to help in engaging the specimens during pull out testing.

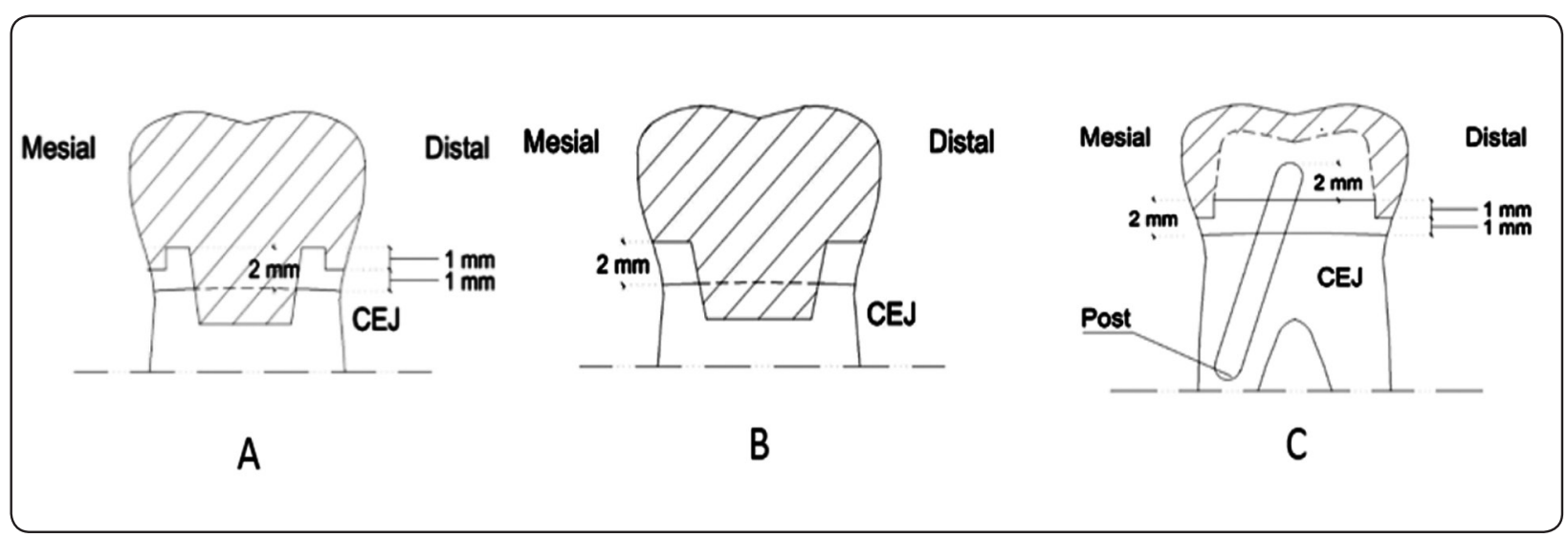

Fig. (1) Schematic diagrams illustrating preparation designs for: A: Endocrown with $1 \mathrm{~mm}$ ferrule B: Endocrown without ferrule C: Post and core supported crown 


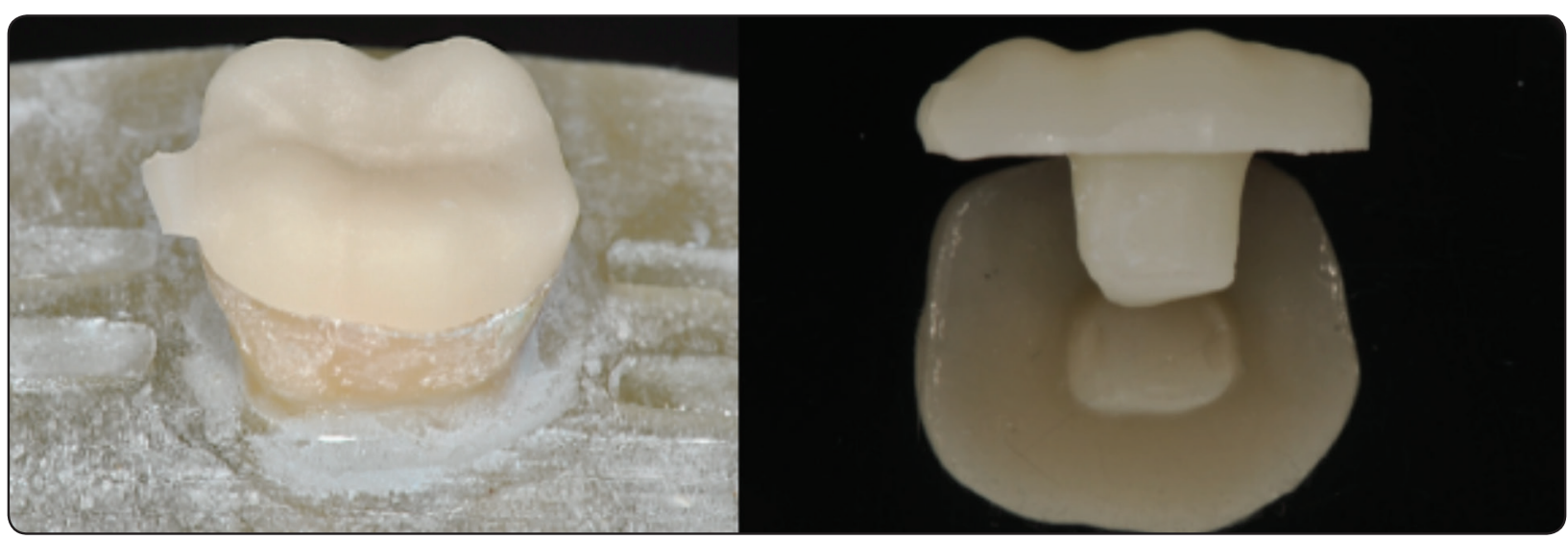

Fig. (2) Empress CAD endocrown before and after glazing

The restorations were milled from IPS Empress CAD and IPS e-max CAD blocks. After milling, The IPS e.max CAD Endocrowns and crowns appeared to be in their pre-crystallized form where they have the bluish-gray color. All specimens were checked on their corresponding teeth for seating under a 3.5 x magnifying Loupes. Programat P300 furnace (Ivoclar Vivadent, Schaan, Liechtenstein) was then used for crystallization and glaze firing. Ceramic crowns were supported by an object fix material and fired on their special firing tray according to the manufacturer's instructions. (Fig. 2)

\section{Cementation Procedures}

The prepared surfaces of the teeth were acid etched using 35\% phosphoric acid then rinsed for 10 seconds. Gentle air dryness was performed on etched tooth surfaces to avoid dentin over dryness. Two successive coats of Adper Single bond 2 adhesive were applied with a micro-brush and gently air-dried for 5 seconds, then light polymerized for 10 seconds.

The intaglio surfaces of each crown were etched using $4.9 \%$ hydrofluoric acid (HF) etching gel (IPS Ceramic Refill, Ivoclar Vivadent, Schaan, Liechtenstein) for 60 seconds for IPS Empress CAD crowns and 20 seconds for IPS e.max CAD crowns according to manufacturer's instructions. RelyX ceramic primer was applied to the etched intaglio surfaces of each crown and allowed to dry for 60 seconds. Then, two successive coats of Adper Single bond 2 adhesive bonding agent were applied with a micro-brush and gently air-dried for 5 seconds, then light polymerized for 10 seconds.

Rely X ARC dual-cure resin cement was mixed according to the manufacturer's instructions and applied to the fitting surface of each crown. Each crown was seated on its respective tooth with finger pressure, and excess cement was carefully removed from the margins. A customized loading device was then used to apply a constant load of 3 $\mathrm{kg}$ parallel to the long axis of each crown to prevent rebounding of the crown during cementation. The cement was light polymerized for 40 seconds from all surfaces, while for the endocrowns, 60 seconds of light polymerization was done to ensure adequate polymerization through the larger ceramic thickness. Teeth were stored in a water bath until testing.

\section{Vertical marginal gap distance measurement}

Vertical marginal gap distance was measured before and after thermal cycling and mechanical fatigue to detect their effect on the gap distance. For each specimen, 5 points on each surface were captured by CCD digital camera mounted on a stereomicroscope (SZ-PT, Olympus, Japan). A total 
of 20 points per specimen were measured then a mean marginal gap distance for each specimen was calculated using the image analysis software program.

In order to mimic the intra-oral conditions, the cemented specimens were subjected to both thermal cycling and mechanical fatigue in a pneumatic fatigue device. (ACTA Fatigue tester, Netherlands) Mechanical fatigue was performed for 1,200,000 cycles at loads between a minimum of $10 \mathrm{~N}$ and a maximum of $150 \mathrm{~N}$, using a frequency of $1 \mathrm{~Hz}$ in a water bath subjected to temperature changes between $5^{\circ} \mathrm{C}$ and $60^{\circ} \mathrm{C} \pm 2{ }^{\circ} \mathrm{C}$ for 2 minutes immersion time in each dwelling temperature and 2 minutes drying time.The compressive load of the mechanical fatigue test was applied along the long axis of the crown using a custom made load applicator in the form of a rod with a $3.6 \mathrm{~mm}$ diameter round tip and centered on the occlusal surface in three contact points.

\section{Retention test}

A copper metal ring with two holes was fabricated to encircle the crowns. Acrylic screws were placed in the holes in order to engage the undercuts in the crowns during pull out testing. The crowns were dislodged along the long axis of the tooth at a crosshead speed of $0.5 \mathrm{~mm} / \mathrm{min}$ until failure using a universal testing machine. The force in Kilograms $(\mathrm{Kg})$ required to remove the crowns was recorded using computer software.

\section{Statistical analysis}

Data were presented as mean and standard deviation (SD) values. Retention data showed parametric distribution; so regression model using Two-way ANOVA was used in testing significance for the effect of ceramic material, preparation design and their interactions on mean retention values. Repeated measures ANOVA was used in testing significance for the effect of ceramic material, preparation design, thermal cycling and fatigue loading, and their interactions on mean gap distance. Tukey's post-hoc test was used for pairwise comparison between the groups when ANOVA test is significant. The significance level was set at $\mathrm{P} \leq 0.05$. Statistical analysis was performed with IBM $^{\circledR}$ SPSS $^{\circledR}$ Statistics Version 20.

\section{RESULTS}

\section{Vertical marginal gap distance}

The results showed that preparation design, thermal cycling and fatigue loading, and the interaction between the three variables had a statistically significant effect on mean gap distance. Ceramic material had no statistically significant effect on mean gap distance.

\section{Effect of preparation design on vertical marginal gap distance}

Regardless of other variables, endocrowns with $1 \mathrm{~mm}$ ferrule showed the statistically significant highest mean gap distance. There was no statistically significant difference between endocrowns without ferrule and post \& core supported crowns; both showed the statistically significant lowest mean gap distances.

\section{Effect of ceramic material on vertical marginal gap distance}

Regardless of other variables, there was no statistically significant difference between mean gap distances of the Empress CAD and e.max CAD ceramic materials. However, for endocrowns with $1 \mathrm{~mm}$ ferrule; Empress CAD scored statistically significant higher mean marginal gap values than e.max CAD.

\section{Effect of thermal cycling and fatigue loading on vertical marginal gap distance}

There was a statistically significant increase in mean gap distance after thermal cycling and fatigue loading for all test groups.(Table 1 and Fig. 3) 


\section{Retention}

The results showed that ceramic material, preparation design and the interaction between the two variables had a statistically significant effect on mean retention values.

\section{Effect of preparation design on retention}

Regardless of ceramic material, endocrowns with $1 \mathrm{~mm}$ ferrule showed the statistically significant highest mean retention value. Post \& core supported crowns showed statistically significant lower mean value. While, endocrowns without ferrule recorded the statistically significant lowest mean retention value.

\section{Effect of ceramic material on retention}

In both endocrowns with $1 \mathrm{~mm}$ ferrule and post and core supported crowns e.max CAD scored statistically significantly higher mean retention value than Empress CAD, while for the endocrowns without ferrule which represented the least retentive design, there was no statistically significant difference between e.max CAD and Empress CAD. (Table 2 and Fig.4)

TABLE (1): Comparison between gap distances before and after thermal cycling and fatigue loading with each material and each design

\begin{tabular}{|c|c|c|c|c|c|c|}
\hline \multirow{2}{*}{ Material } & \multirow[b]{2}{*}{ Design } & \multicolumn{2}{|c|}{$\begin{array}{c}\text { Before thermal cycling } \\
\text { and fatigue loading }\end{array}$} & \multicolumn{2}{|c|}{$\begin{array}{l}\text { After thermal cycling } \\
\text { and fatigue loading }\end{array}$} & \multirow{2}{*}{$P$-value } \\
\hline & & Mean & SD & Mean & SD & \\
\hline \multirow{3}{*}{$\begin{array}{c}\text { Empress } \\
\text { CAD }\end{array}$} & Endocrowns with $1 \mathrm{~mm}$ ferrule & 87.8 & 4.5 & 89.8 & 5.5 & $0.005^{*}$ \\
\hline & Endocrowns without ferrule & 79.2 & 2.9 & 81.8 & 2 & $0.045^{*}$ \\
\hline & Post \& Core supported crowns & 78.7 & 1.4 & 81.5 & 1.4 & $<0.001 *$ \\
\hline \multirow{3}{*}{$\begin{array}{l}\text { e.max } \\
\text { CAD }\end{array}$} & Endocrowns with $1 \mathrm{~mm}$ ferrule & 82.8 & 2.5 & 84.2 & 1.6 & $0.010^{*}$ \\
\hline & Endocrowns without ferrule & 78.3 & 3.4 & 82.3 & 2.1 & $<0.001 *$ \\
\hline & Post \& Core supported crowns & 78.5 & 2.7 & 81.4 & 1.5 & $<0.001 *$ \\
\hline
\end{tabular}

*: Significant at $P \leq 0.0$

TABLE (2): Comparison between retention values of ceramic materials with each preparation design

\begin{tabular}{|c|c|c|c|c|c|}
\hline \multirow{2}{*}{ Mesign } & \multicolumn{2}{|r|}{ Empress CAD } & \multicolumn{2}{c|}{ e.max CAD } & \multirow{2}{*}{ P-value } \\
\cline { 2 - 6 } & Mean & SD & Mean & SD \\
\hline Endocrowns with 1 mm ferrule & 12.4 & 1.2 & 14.7 & 0.9 & $0.025^{*}$ \\
\hline Endocrowns without ferrule & 10.5 & 0.5 & 10.6 & 0.7 & 0.895 \\
\hline Post \& Core supported crowns & 11.3 & 0.6 & 13.5 & 0.8 & $0.040^{*}$ \\
\hline
\end{tabular}




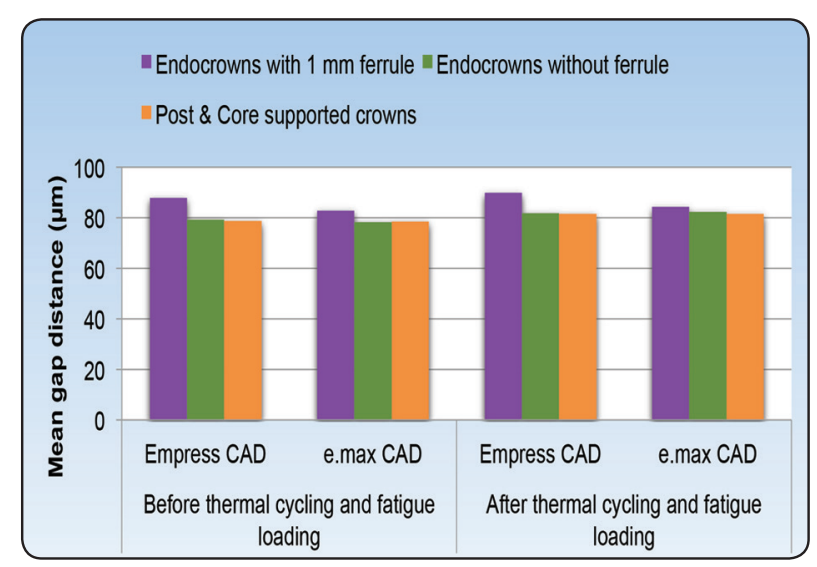

Fig. (3) Bar chart representing mean values for gap distances for different groups

\section{DISCUSSION}

Endodontically treated teeth with inadequate remaining tooth structure require foundation restoration to increase resistance and retention form for definitive restoration. However, the price of added resistance and retention may lead to an increased risk of damaging tooth structure. ${ }^{(22,23)}$ With the introduction of improved dentin adhesives and new ceramic materials, bonded ceramic restorations are recognized as alternatives to conventional crowns which require macromechanically styled destructive preparations. (11) Therefore, it is now possible to deviate from the classic preparation technique to what is called the "endo" preparation technique and use endocrowns in the restoration of endodontically treated teeth. ${ }^{(24)}$ Since endocrowns are documented as a feasible restorative approach, therefore, the main interest of the present research was directed towards evaluating the vertical marginal gap distance and retention of Cerec endocrowns compared to conventional post and core supported crowns.

Selection of teeth of average sizes and shapes was performed before testing to minimize possible variations and errors. All teeth were decapitated perpendicular to the long axis $2 \mathrm{~mm}$ coronal to the proximal CEJ in order to simulate the compromised

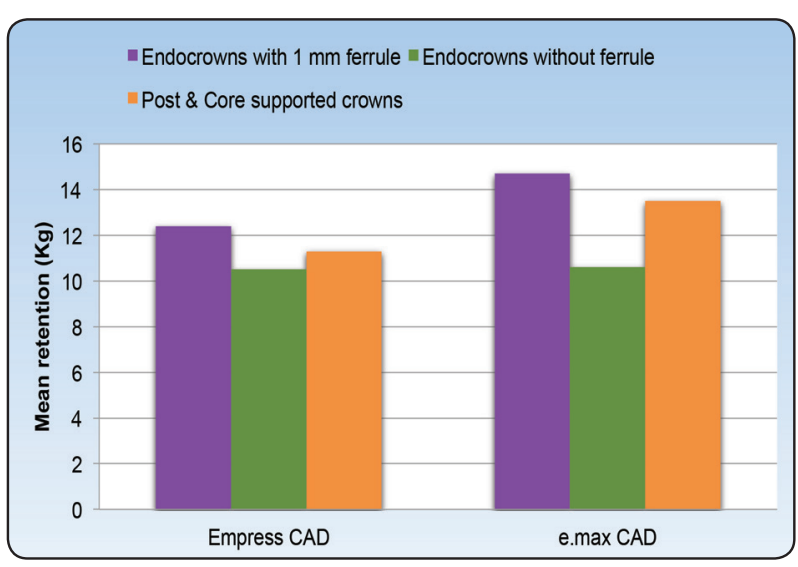

Fig. (4) Bar chart representing mean retention values for different groups

condition of severely damaged endodontically treated molars. ${ }^{(25)}$ Teeth were prepared according to clinically established preparation criteria for all ceramic endocrowns and crowns (26) using a special milling machine to ensure standardization of the preparations. For samples standardization, a Biogeneric-copy mode in the Cerec software 4.0 was used, so that each artificial crown is designed and milled as an exact replica of the unprepared anatomy. Although various machinable materials are available for fabricating all ceramic crowns using CAD/CAM systems, IPS Empress CAD and IPS e.max CAD blocks were chosen because they have the advantages of long term clinical acceptability, good bonding characteristics, short laboratory steps, favorable esthetics and lack for veneering porcelain need. ${ }^{27,28)}$

A strict adherence to the bonding and luting protocols for ceramic materials and cement used was followed according to the manufacturer's recommendations in order to eliminate variables during bonding and luting procedures and ensure a close simulation of clinically relevant conditions. ${ }^{(29,30)}$ It is generally agreed that resin cement bonding to the tooth and crown through both chemical and micromechanical bonding decreases the marginal discrepancy and provides high retention. ${ }^{(18,31)}$ 
Thermal cycling and fatigue loading were performed for all the specimens to mimic the oral conditions as they were proved to have an effect on marginal fit and retention of dental ceramics. Mechanical fatigue was performed for $1,200,000$ cycles in order to simulate a clinical service time of 5 years. ${ }^{(32,33)}$

The vertical marginal gap measurement was selected as the most frequently used method to quantify the accuracy of a restoration ${ }^{(34,35)}$.In spite of the presence of various testing methods and measuring tools, the stereomicroscope was the adopted method for measuring the cervical marginal accuracy, as it allowed long-term study, without sacrificing the samples ${ }^{(36,37)}$. The measurement was performed at 20 points along the cervical circumference of each crown.

The results obtained in this study showed that endocrowns with $1 \mathrm{~mm}$ ferrule reported a statistically significant higher mean vertical marginal gap value. There was no statistically significant difference in mean marginal gap values between endocrowns without ferrule and post \& core supported crowns. A possible explanation for the higher vertical marginal gap values of endocrowns with $1 \mathrm{~mm}$ ferrule might be the more complicated design of the restoration and the irregular surface topography of the preparation. Also, thinner ceramic thickness at the ferrule area can make the production of accurate margins more challenging. ${ }^{(38)}$ These results were concurrent with the findings of Forberger and Gohring, $2008{ }^{(39)}$ who reported a poorer marginal continuity for ceramic endocrowns with ferrule compared to post and core supported crowns.

Regarding the ceramic material, there was no statistically significant difference between mean vertical marginal gap values of the Empress CAD and e.max $\mathrm{CAD}$ ceramic materials, however, for endocrowns with $1 \mathrm{~mm}$ ferrule; Empress CAD scored statistically significant higher mean marginal gap values than e.max CAD. This may be attributed to the difference in brittleness index between
Empress Cad and e.max CAD ceramic materials. Brittleness index (B) was proposed by Boccaccini ${ }^{(40)}$ as a parameter for estimating the machinability and chipping tendency of glass ceramics given by the ratio of hardness $(\mathrm{H})$ to fracture toughness $\left(\mathrm{K}_{\mathrm{Ic}}\right)\left(\mathrm{B}=\mathrm{H} / \mathrm{K}_{\mathrm{Ic}}\right)$. The lower the brittleness index, the higher the machinability and the lower the tendency of marginal chipping. By applying to Boccaccini's equation, Empress CAD scored higher brittleness index $\left(4.769 \mathrm{MPa} / \mathrm{MPa} \mathrm{m}^{1 / 2}\right)$ than e.max $\mathrm{CAD}$ (4.480 $\mathrm{MPa} / \mathrm{MPa} \mathrm{m}^{1 / 2}$ ), which increases the potential for microscopic chipping of the ceramic at the margins of the complicated design endocrown with $1 \mathrm{~mm}$ ferrule during milling. ${ }^{(41)}$ This assumption was supported by Tsitrou et al., $2007^{(42)}$ who claimed that a ceramic material with a greater level of chipping during milling is likely to have a reduced marginal quality. Also the lower marginal gap values of e.max CAD endocrowns with $1 \mathrm{~mm}$ ferrule compared to Empress CAD may be linked to the higher edge strength of lithium disilicate ceramics compared to other glass ceramics. ${ }^{(28,43)}$

Results also showed a statistically significant increase in mean vertical marginal gap distance after thermal cycling and fatigue loading for all tested specimens. This increase may be linked to the thermal cycling. It has been suggested that thermal cycling may stress and weaken the adhesive bond, and causes thermal dimensional changes in the resin cement leading to an increase in the interfacial gap along the margins of the restoration. ${ }^{(44,45)}$ It might be also related to fatigue loading, where it was reported that specimens loaded for $10^{5}$ cycles showed an increase in marginal gaps at tooth-restoration interface. This increase may be induced by the deformation of the dentin interface. ${ }^{(46)}$ These results were in accordance with the findings of Forberger and Gohring, $2008{ }^{(39)}$ who demonstrated that thermal cycling and fatigue loading decreased the marginal integrity of ceramic endocrowns and glass fiber post and core supported crowns. 
Despite the increase in the vertical marginal gap values after thermal cycling and fatigue loading, all the obtained data in this study fell within the clinically accepted values, since it was proposed that a restoration would be clinically successful if a marginal gap of less than $120 \mu \mathrm{m}$ could be achieved. ${ }^{(47)}$, while other studies agreed that marginal gap should not be greater than $100 \mu \mathrm{m} .{ }^{(48,49)}$

Regarding the retention, the results obtained in this study showed that the preparation design; endocrowns with $1 \mathrm{~mm}$ ferrule reported statistically significant higher mean retention values than post \& core supported crowns and endocrowns without ferrule. This finding is probably related to the greater surface area for bonding in endocrowns with $1 \mathrm{~mm}$ ferrule $\left(94 \mathrm{~mm}^{2}\right)$ compared to post and core supported crowns $\left(84 \mathrm{~mm}^{2}\right)$ and endocrowns without ferrule $\left(82 \mathrm{~mm}^{2}\right)$. It has been demonstrated that the increase in the surface area of resin cement coverage positively influence the retention of ceramic crowns. (50) It may be also linked to the unique design of the endocrown with $1 \mathrm{~mm}$ ferrule; where it utilizes the pulp chamber for macro mechanical retention provided by pulpal walls as well as micro retention attained with the use of adhesive cementation ${ }^{(51)}$. In addition it embraces the whole circumference of the tooth extra coronally thus providing both external and internal retention. Results also demonstrated that post \& core supported crowns showed statistically significant higher mean retention values than endocrowns without ferrule. This can be also attributed to the greater surface area available for bonding.

Regarding the material of construction; e.max CAD scored statistically significantly higher mean retention value than Empress CAD in both endocrowns with $1 \mathrm{~mm}$ ferrule and post and core supported crowns, while for the endocrowns without ferrule which represented the least retentive design, there was no statistically significant difference between e.max CAD and Empress CAD. This may be attributed to the difference in the composition and material properties between Empress CAD and e.max CAD which may influence the bond strength between ceramic surface and resin cement. ${ }^{(52)}$ These results were concurrent with Trindade, $2012{ }^{(52)}$ who reported high bond strength between lithium disilicate ceramics and Rely x ARC resin cement. Moreover, Nhan et al., $2009{ }^{(53)}$ reported that e.max CAD demonstrated higher bond strength with Rely $\mathrm{x}$ ARC resin cement than Empress CAD.

Very few studies have dealt with the retention of all ceramic crowns; therefore, further investigations are needed to assess the retention of glass ceramic endocrowns as well as conventional crowns. According to the previous discussion, our results supported the hypothesis that endocrowns achieve survival rates similar to post and core supported crowns.

\section{CONCLUSIONS}

Within the limitations of this study, the following conclusions can be drawn;

1- Endocrowns represent a successful conservative alternative to post and core supported crowns for restoring mutilated endodontically treated posterior teeth.

2- All tested endocrown designs with both materials proved to have a clinically acceptable marginal gap distances.

3- Preparation geometry for endocrown designs is a crucial factor for the retention of this kind of restorations.

\section{REFERENCES}

1- Caputo, A.A. and Standlee, J.P.: Biomechanics in clinical dentistry. Chicago Quint. 1987;134:185-203.

2- Caputo, A.A. and Standlee, J.P.: Pins and Posts-why, when and how? Dent. Clin. North Am. 1976;20:299-311.

3- Sorensen, J.A. and Martinoff, J.T.: Intracoronal reinforcement and coronal coverage-a study of endodontically treated teeth. J. Prosthet. Dent. 1984; 51:780-784. 
4- Huang, T.J.; Schilder, H. and Nathanson, D. : Effects of moisture content and endodontic treatment on some mechanical properties of human dentine. J. Endod. 1992;18:209-215.

5- Schwartz, R.S. and Robbins, J.W.: Post placement and restoration of endodontically treated teeth: a literature review. J. Endod. 2004;30:289-301.

6- Papa, J.; Cain, C. and Messer, H.H.: Moisture content of vital versus endodontically treated teeth. Endod. Dent. Traumatol 1994;10:91-93.

7- Reeh, E.S.; Messer, H.H. and Douglas, W.H.: Reduction in tooth stiffness as a result of endodontic restorative procedures. J. Endod. 1989;15:512-516.

8- Finger, W.J. and Fritz, V. : Laboratory evaluation of onecomponent dentin bonding agents. Am. J. Dent. 1996;206210 .

9- Qing, H.; Zhu, Z.; Chao,Y. and Zhang, W.: In vitro evaluation of the fracture resistance of anterior endodontically treated teeth restored with glass fiber and zirconia posts, J. Prosthet. Dent. 2007;97:93-98.

10- Miyazaki, M.; Sato, M.; Onose, H. and Moore, B.K.: Influence of thermal cycling on dentin bond strength of twostep bonding systems. AM. J. Dent. 1998;11:118-122.

11- Frankenberger, R.; Kramer, N. and Petschelt, A.: Technique sensitivity of dentin bonding effect of application mistakes on bond strebgth and marginal adaptation. Oper. Dent. 2000;25:324-330.

12- Reich, S.M.; Wichmann, M. and Rinne, H.: Clinical performance of large all ceramic CAD/CAM generated restorations after three years, a pilot study. J. Am. Dent. Assoc. 2004;135:605-612.

13- Dietschi, D.; Duc, O.; Krejci, I. and Saclan, A.: Biomechanical considerations for the restoration of endodontically treated teeth: a systematic review of the literature, Part II. Quint. Int. 2008;39:117-129.

14- Lander, E. and Dietschi, D.: Endocrowns: a clinical report. Quint. Int. 2008;39:99-109

15- Ferrari, M.; Cagidiaco, M.C.; Vichi, A.; Mannocci, F.; Mason, P.N. and Mjor, I.A.: Bonding of all-porcelain crowns: Structural characteristics of the substrate. Dent. Mater. 2001;17:156-164.

16- Goldin, E.B.; Boyd, N.W.; Goldstein, G.R.; Hittelman, E.L.; Edd, M.A. and Thompson, V.P.: Marginal fit of leucite- glass pressable ceramic restorations and ceramic-pressedto-metal restorations. J. Prosthet. Dent. 2005;93:143-147.

17- Suarez, M.J.; Villaumbrosia, P.G.; Pradies, G. and Lozano, J.F.L.: Comparison of the marginal fit of Procera all-ceram crowns with two finish lines. Int. J. Prosthodont. 2003; 16:229-232.

18- Gu, H. and Kern, M. : Marginal discrepancies and leakage of all ceramic crowns: influence of luting agents and aging conditions. Int. J. Prosthodont. 2003;16:109-116.

19- Tuntiprawon, M.: Effect of tooth surface roughness on marginal seating and retention of complete metal crowns. J. Prosthet. Dent. 1999;81:142-147.

20- Ana, M.D.; Arnold, M.A. and Debra, R.: Current status of luting agents for fixed Prosthodontics. J. Prosthet. Dent. 1999; 81:135-141.

21- Ohayama, T.; Yoshinari, M. and Oda, Y.: Effects of cyclic loading on the strength of all-ceramic materials. Int. J. Prosthodont.1999;12:28-37.

22- Christensen, G.J.: When to use fillers, build-ups or posts and cores. J. Am. Dent. Assoc. 1996;127:1397-1398

23- Trier, A.C. ; Parker, M.H. ; Cameron, S.M. and Broussean, J. : Evaluation of resistance form of dislodged crowns and retainers. J. Prosthet. Dent. 1998;80:405-409.

24- Rathke, A.; Mormann, W.H. and Luthy, H.: Strength of Cerec crowns on different preparations, In: Mormann WH (ed) CAD/CAM in Esthetic Dentistry. Chicago-Quintessence 1996:483-494.

25- Chang, C.Y.; Kuo, J.S.; Lin, Y.S. and Chang, Y.H.: Fracture resistance and failure modes of CEREC endocrowns and conventional post and core-supported CEREC crowns. J. Dent. Sci. 2009;4(3):110-117.

26- Bindl, A. and Mörmann, W.H.: Clinical evaluation of adhesively placed Cerec Endocrowns after 2 years - Preliminary results. J. Adhes. Dent. 1999;1:255-265.

27- IPS Empress CAD Scientific Documentation. Amherst, NY: Ivoclar Vivadent, Nov. 2006.

28- Tysowsky, G.: The science behind lithium disilicate: today's surprisingly versatile, esthetic \& durable metal-free alternative. Oral Health J. 2009;March:93-97.

29- Bindl, A.; Richter, B. and Mörmann, W.H.: Survival of ceramic computer-aided design/manufacturing crowns bonded to preparations with reduced macroretention geometry. Int. J. Prosthodont. 2005;18:219-224. 
30- Goto, Y.; Nicholls, J.I.; Phillips, K.M. and Junge, T.: Fatigue resistance of endodontically treated teeth restored with three dowel-and-core systems. J. Prosthet. Dent. 2007;93:45-50.

31- Blatz, M.B.; Sadan, A. and Kern, M.: resin-ceramic bonding: A review of the literature. J. Prosthet. Dent. 2003;89:268-274.

32- Kelly, J.R.: Clinically relevant approach to failure testing of all ceramic restorations. J. Prosthet. Dent. 1999;81:652661.

33- Sakaguchi, R.L.; Douglas, W.H.; DeLong, R. and Pintado, M.R.: The wear of a posterior dental composite in an artificial mouth: a clinical correlation. Dent. Mater.1985;1:238-242.

34- Groten, M.; Girthofer, S . and Probster, L.: Marginal fit consistency of copy-milled all-ceramic crowns during fabrication by light and scanning electron microscopic analysis. J. Oral Rehabil. 1997;24:871-881.

35- Petteno, D.; Schierano, G.; Bassi, F. and Carossa, S.: Comparison of marginal fit of three different metal ceramic systems. Int. J. Prosthodont. 2002;13:405-408.

36- Beschnidt, S.M. and Strub, J.R. : Evaluation of the marginal accuracy of different all-ceramic crown systems after simulation in the artificial mouth. J. Oral Rehabil. 1999;26:582-593.

37- Ferrari, M. ; Mason, P. and Poli, L.: Marginal adaptation of crowns: a scanning electron microscopic investigation. Int. J. Periodont. And Rest. Dent. 1994;14:273.

38- Souza, A.; Ozcan, M., Pavanelli, C.A.; Buso, L.; Lombardo, G.H.; Michida, S.M.; Mesquita, A.M. and Bottino, M.: Marginal and internal discrepancies related to margin design of ceramic crowns fabricated by a CAD/CAM System. J. Prosthodont. 2011;2:1-7.

39- Forberger, N. and Gohring, T.: Influence of the type of post and core on in vitro marginal continuity, fracture resistance, and fracture mode of Lithia disilicate-based allceramic crowns. J. Prosthet. Dent. 2008;100:264-273.

40- Boccaccini, A.R.: Machinability and brittleness of glassceramics. J. Mater. Process. Tech. 1997;65:302-304.
41- Giannetopoulos, S.; Van noort, R. and Tsitrou, E.A.: Evaluation of the marginal integrity of ceramic copings with different marginal angles using two different CAD/CAM systems. J. Dent. 2010;38:980-986.

42- Tsitrou, E.A.; Northeast, S.E. and Van noort, R.: Brittleness index of machinable dental materials and its relation to the marginal chipping factor. J. Dent. 2007;35:897-902.

43- El-Meliegy, E. and Van noort, R.: Glasses and Glass Ceramics for Medical Applications. Lithium Disilicate Glass Ceramics. 209-218. Springer 2012.

44- Drummond, J.; Novickas, D. and Lenke, J.: Physiological aging of an all-ceramic restorative material. Dent. Mater.1991;25:133-135.

45- Relief, D.H.: Do adhesives prevent microleakage? Int. Dent.J.1994;44:19.

46- Akkayan, B. and Gulmez, T.: Resistance to fracture of endodontically treated teeth restored with different post systems. J. Prosthet. Dent. 2002;87:431-437.

47- Sulaiman, F. ; Chai, J. ; Jamerson, L.M. and Wozniak, W.T. : A comparison of the marginal fit of In-Ceram, IPS Empress and Procera crowns. Int. J. Prosthodont. 1997;10:478-484.

48- Mormann, W.H. and Bindl, A.: The Cerec 3 a quantum leap for computer-aided restorations: initial clinical results. Quint. Int. 2000;31:699-712.

49- Hunter, A.J. and Hunter, A.R. : Gingival margins for crowns: A review and discussion, Part II: discrepancies and configurations. J. Prosthet. Dent. 1990;64:636-642.

50- Christensen, G.J.: Ensuring retention for crowns and fixed prosthesis. J. Am. Dent. Assoc. 2003;134:993-995.

51- Biacchi, G.R. and Basting, R.G.: Comparison of Fracture Strength of Endocrowns and Glass Fiber Post- Retained Conventional Crowns. Oper. Dent. 2011;36:1-6.

52-Trindade, F.Z.: Effect Of The Ceramic-Composition And Manufacturing-Process On Resin Cement-Ceramic bond strength. IADR General Session and Exhibition; Iguacu Falls, Brazil. June 2012

53- Nhan, R.; Ripps, A. and Xu, X.: Shear Bond Strengths with eMax CAD and Empress CAD Ceramics. IADR General Session and Exhibition; Miami, Florida. April 2009. 